\title{
Influences of Human Operators on the Logistics of Manufacturing Cells
}

\author{
Gregor von Cieminski and Peter Nyhuis \\ University of Hannover, Institute of Production Systems and Logistics (IFA), Callinstrasse 36, \\ D-30161 Hannover, Germany. \\ Email: \{cieminski,nyhuis\}@ifa.uni-hannover.de
}

\begin{abstract}
Human operators have important influences on the logistic behaviour of manufacturing cells. In many of the possible configurations of a manufacturing cell, operators represent the bottleneck of the cell. Thus they dominate the cell's logistic behaviour. This paper explains how the theory of logistic manufacturing cell operating curves considers human influences on manufacturing cell logistics. The operating curves are a tool to analyse the logistic performance of manufacturing cells. Therefore they represent a means for determining logistically suitable configurations of the human-machine interactions between the human operators and the work systems in manufacturing cells.
\end{abstract}

Key words: Manufacturing cells, Logistic operating curves, Human aspects

\section{HUMAN OPERATORS IN MANUFACTURING CELLS}

Human operators fulfil important roles in manufacturing cells. When cellular manufacture first came to widespread use in the 1980 s, one of the foci of scientific research and practical applications lay on their human aspects (GREEN, SADOWSKI 1984). A substantial body of work was produced on the ergonomic and organisational aspects involving human operators. Job and workplace design were important themes as well the introduction of team working principles (SCHONBERGER 1990). Manufacturing cells were the first type of manufacturing system that integrated elements of management functions in shop floor operations: Decentralised production 
planning and control, quality management, maintenance and other management functions all form part of the responsibilities of the operators on the shop floor. Furthermore, numerous studies on manufacturing cells concerned themselves with job enlargement and job enrichment as well as employee empowerment (SLACK, CHAMBERS, JOHNSTON 2000). An analysis of the logistic behaviour of manufacturing cells, however, has to intentionally neglect the practicability of ergonomic and organisational aspects and has to purely concentrate on the effects of human action on the logistic performance of the cells.

This paper introduces the logistic manufacturing cell operating curves as a model of the logistic behaviour of manufacturing cells (WIENDAHL, CIEMINSKI 2003). It describes how the general modelling methodology is capable of considering the particular logistic characteristics of manufacturing cells whose logistic behaviour depends on human operators. General observations on the human influence on manufacturing cell logistics are presented. Also, the paper provides guidelines as to how industrial companies can most effectively configure cells staffed by human operators.

\section{LOGISTIC MODELLING OF MANUFACTURING CELLS}

Until recently, the lack of models of the logistic behaviour of manufacturing cells meant that the precise human influence on their logistic performance could not be determined (MILTENBURG 2001). Recommendations exist as to how human operators best contribute to a smooth material flow in manufacturing cells. These consider ergonomic issues on a practical level rather than examining measures of logistic performance. Industrial companies therefore experience difficulties in finding logistically adequate set-ups of manufacturing cells when implementing these. The theory of the logistic manufacturing cell operating curves represents a valid model for the logistic behaviour of manufacturing cells (WIENDAHL, CIEMINSKI 2003). The logistic operating curves describe the behaviour of the logistic performance measures output rate and throughput time as depending on the work-in-process (WIP) level of a manufacturing cell. The mathematical model underlying the operating curves incorporates the particular logistic characteristics of manufacturing cells. These serve as boundary conditions for the mathematical model. Figure 1 depicts the schematic view of a manufacturing cell that conforms to the boundary conditions. The most important logistic characteristic of manufacturing cells is that the parts of batch orders arriving at, and departing from, the cell are transported in one-piece flow in between its work systems (see Figure 1). 


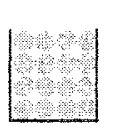

c

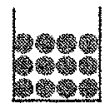

b

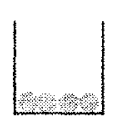

a
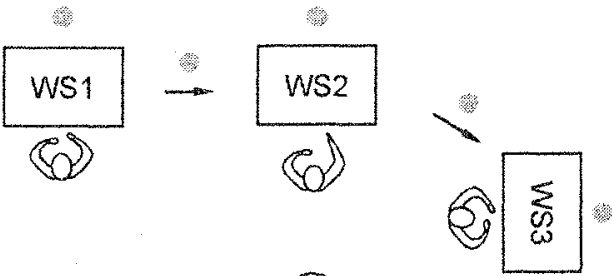

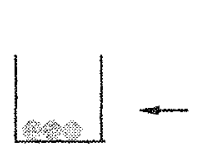

a

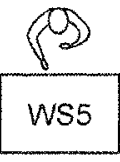

磨

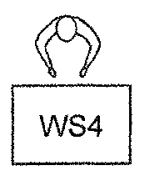

綵

WS: Work system

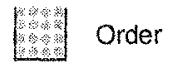

* Parts of an order

Figure l. General structure of a manufacturing cell

WIENDAHL and CIEMINSKI (2003) cover the modelling methodology, its logistic boundary conditions and its mathematical algorithm as well as the formulae in detail. They explain how approximation equations for the aforementioned interdependencies between the WIP level and the output rate and the throughput time of a manufacturing cell can be developed. Figure 2 shows the shape of the approximate operating curves.

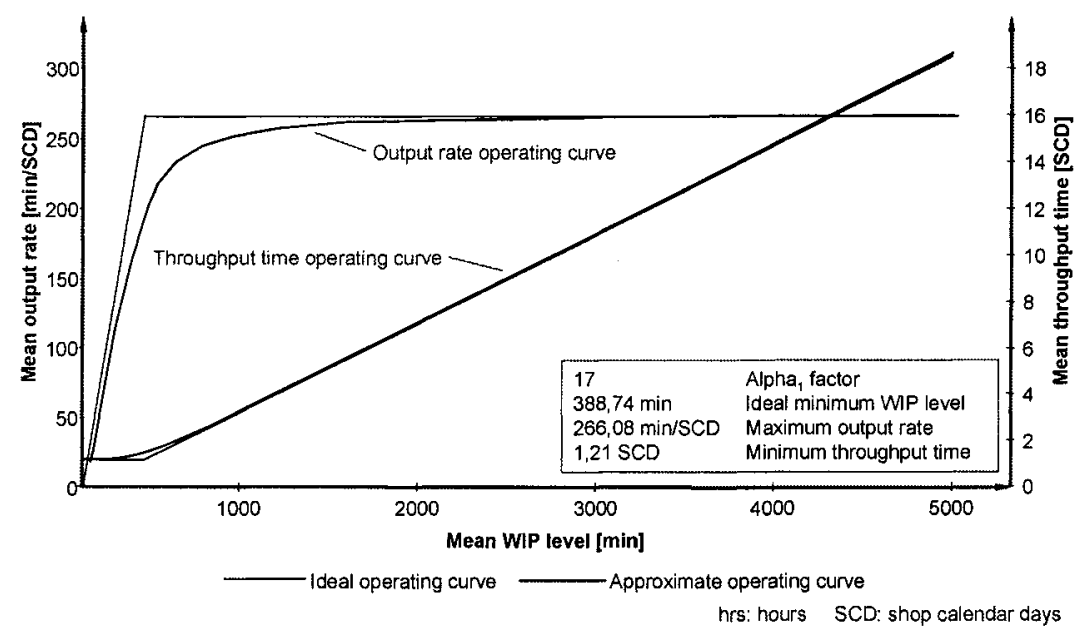

Figure 2, Logistic manufacturing cell operating curves 
The mean output rate of a manufacturing cell increases proportionately to rising WIP levels until the capacity limit of the cell is reached. The mean throughput time remains constant up to this particular WIP level. If the WIP level rises further, queues of waiting orders build so that the mean throughput time increases (see Figure 2).

It is important to note that the general model of a manufacturing cell as depicted in Figure 1 assumes that operators service all work systems within the cell. The human resources therefore have no actual influence on the order fulfilment process. The logistic bottleneck of the cell is determined purely by the work system with the maximum processing time. Manufacturing cells implemented in industry normally differ from this simplified structure. Here, the number of active operators in a manufacturing cell is usually reduced so that the influences of the human operators on the logistic processes become evident. Equation 1 defines the work content of manufacturing cells and can be used to explain the human influence:

$$
T O_{M C}=\frac{T 1_{n}+(L S-1) \cdot T C Y C L E}{60}
$$

$\begin{array}{ll}T O_{M C} & \text { order work content of manufacturing cell [hrs] } \\ T 1_{n} & \text { initial output time at nth work system in mftg. cell [min] } \\ n & \text { number of work systems in manufacturing cell [units] } \\ L S & \text { lot size [units] } \\ T C Y C L E & \text { cycle time [min] }\end{array}$

The work content of orders determines the WIP level of manufacturing cells as well as their output rate and load. The cycle time TCYCLE in equation (1), which is equal to the processing time of the bottleneck of the manufacturing cell, has a dominating effect on the work content of orders. Configurations of manufacturing cells exist, in which the cycle time is determined by the activities of the human operators (loading, setting-up and unloading of work systems). This is the case if the duration of the activities an operator has to carry out during one cycle exceeds the maximum processing time of the work systems in the manufacturing cell. The operator becomes the bottleneck of the cell. The activities assigned to the operators depend on the configurations of the manufacturing cells. Figure 3 shows the typical relations between the human operators and the parts processed in a manufacturing cell (TAKEDA 1996). According to the "caravan" logic operators carry a single part through the entire manufacturing cell (see Figure 3a). Following the "relay" logic, parts are passed between operators as in an athletics "relay" (see Figure 3b). In case of the "pool" logic, operators are responsible for operations at certain work systems but are free to move whichever work system that requires attention (see Figure 3c). 


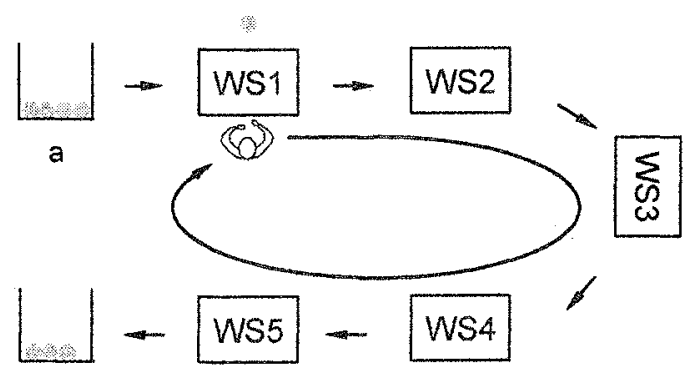

a

a) Operator movements according to "caravan" logic

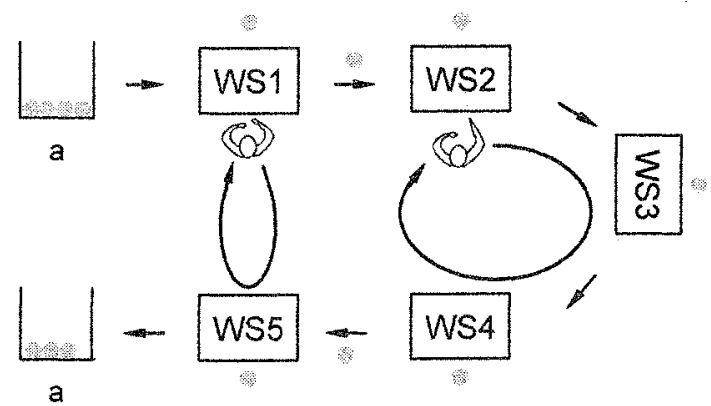

b) Operator movements according to "relay" logic

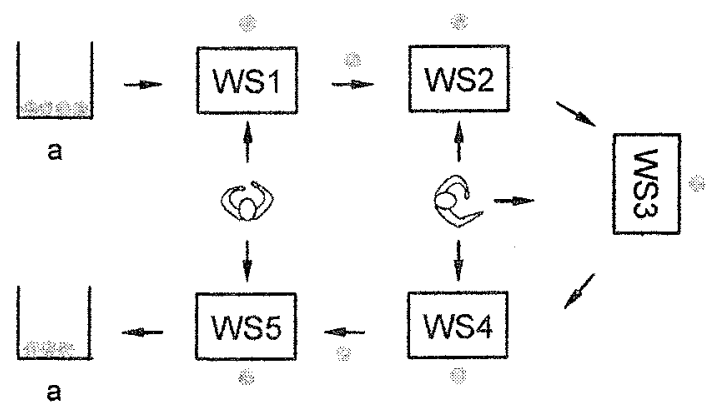

c) Operator movements according to "pool" logic

WS: Work system $\square$ Order Parts of an order

Figure 3. Operator movements in manufacturing cells

(Source: CIEMINSKI, NYHUIS 2003, p. 143; supplemented)

The number of operators working in a manufacturing cell can vary for all three movement logics. Also, a number of different assignments of operators to work systems and of different specifications of the sequence of activities are feasible. The cycle time determined by the human operators is longest for the caravan logic. In this case, the cycle time is equal to the duration of time 
it takes an operator to pass all work systems of the cell. The only real difference between the relay logic and the pool logic is that the sequence of activities of the operators is fixed in the relay set-up. Pool configurations make full use of the flexibility of the operators. Therefore, their cycle times are normally lower than for relay configurations. The prerequisite for installing both kinds of configurations, however, is that the operators are qualified to use several, if not all, work systems within the cell.

\section{DETERMINING THE LOGISTIC EFFECTS OF HUMAN ACTIVITIES}

In order to determine the logistic performance of manufacturing cells with different specifications of the activities of the human operators, simulation experiments were carried out. These examined the behaviour of a simulation model modelling a real manufacturing cell designed for an industrial company. The model had been validated in earlier experiments that did not consider the human aspects of the logistic behaviour. In a series of experiments the logic of operator movements, the sequence of activities and the number of operators working in the cell were varied. All models processed the same random sequence of orders so that the logistic performance measures recorded in the experiments were directly comparable.

The first finding of the simulation experiments was that it is not possible to establish a mathematical equation for the manufacturing cell cycle time if this depends on the human operators working in the cell. Diverse dynamic logistic interactions between operators and work systems occur for different cell configurations. These cannot be expressed mathematically by a single approximation equation. Furthermore, the dynamic processes lead to operator waiting times that form a part of the cycle time. The waiting times can only be predetermined analytically by means of Gantt charts or other project planning methods. Figure 4 shows an example of such a Gantt chart. One operator is responsible for the loading and unloading of all work systems in the manufacturing cell. The manufacturing cell has reached a stable logistic state and the sequence of activities shown repeats itself. It is immediately obvious is that the low number of operators causes a high degree of idle times for the work systems. The machines have to wait until the operator has finished activities at other work systems. Even though the work systems are not fully utilised, there is a period of an operator waiting time. During this work systems 1,2,4 and 5 are busy and there are no parts available that could be loaded onto work system 3 (see Figure 4). 


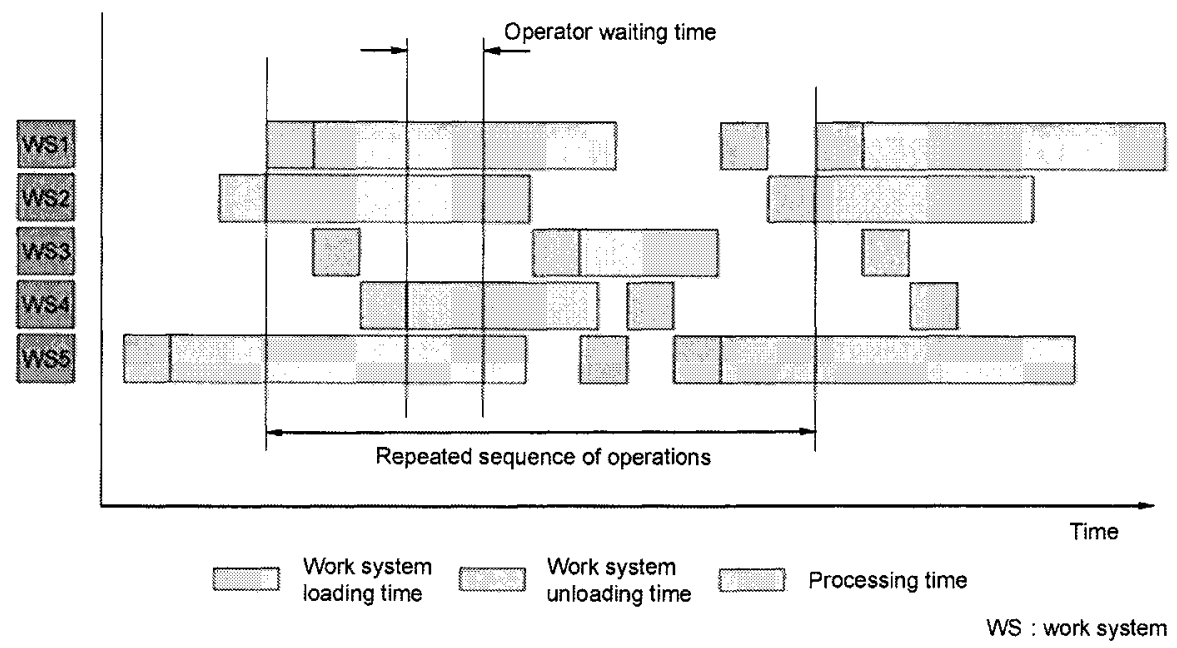

Figure 4. Determination of operator cycle time using Gantt charts

In the simulation experiments, the cycle times were therefore measured rather than predetermined. It was found that using the measured cycle time values, the logistic operating curves could still be applied. It follows, that companies that are setting up new manufacturing cells or reconfiguring existing ones should measure the operator cycle times of the cells in order to be able to determine their logistic performance.

The simulation experiments were secondly used to determine the effects the number of operators had on the logistic performance. These effects can be expressed in terms of the cycle time and the output rate of the manufacturing cells. Table 1 shows the variation of the measured cycle time for different configurations of the manufacturing cell modelled in the simulation experiments.

On the one hand, the experiments proved that manufacturing cell configurations using the pool logic lead to the shorter operator cycle times than configurations of the caravan or relay logic. The utilisation of operators for pool configurations was higher which resulted in reduced operator cycle times. The figures in Table 1 relate to configurations using the pool logic.

On the other hand, variations of the assignments of operators to work systems showed that the operators represent the manufacturing cell bottleneck in the minority of all possible configurations. The likelihood of operators becoming bottlenecks increases if the number of operators working in a manufacturing cell is low. For cost reasons, companies prefer these configurations despite the logistic disadvantages that arise. Even in such circumstances possibilities exist to reduce the extent of these disadvantages. A comparison of the cycle times between manufacturing cells with balanced 
operator workloads and imbalanced ones shows that it is logistically preferable to assign operators to work systems in such a way that the total processing times per operator are balanced (see Table 1). Such configurations minimise the operator cycle time. Also, the assignment of an operator to the first and last work system of a cell, which is sometimes recommended in literature as a link between the cell and the overall material flow (TAKEDA 1996), was found to lead to particularly high operator cycle times. It should therefore be avoided.

Table I. Cycle times of different manufacturing cell configurations

\begin{tabular}{|c|c|c|c|}
\hline $\begin{array}{c}\text { Allocation of } \\
\text { operators }\end{array}$ & $\begin{array}{c}\text { Cycle time } \\
\text { product 1[min] }\end{array}$ & $\begin{array}{c}\text { Cycle time } \\
\text { product 2 [min] }\end{array}$ & $\begin{array}{c}\text { Cycle time } \\
\text { product 3 [min] }\end{array}$ \\
\hline $\begin{array}{c}\text { 1 operator at each } \\
\text { work system }\end{array}$ & 4.8 & 4.8 & 4.1 \\
\hline $\begin{array}{c}\text { More than } \\
\text { 2 operators }\end{array}$ & 4.8 & 4.8 & 4.1 \\
\hline $\begin{array}{c}\text { 2 operators with } \\
\text { balanced workload }\end{array}$ & 4.8 & 4.8 & 4.1 \\
\hline $\begin{array}{c}\text { 2 operators with } \\
\text { imbalanced workload }\end{array}$ & 5.3 & 5.3 & 4.6 \\
\hline $\begin{array}{c}\text { 1 operator in } \\
\text { manufacturing cell }\end{array}$ & 6.1 & 6.3 & 5.1 \\
\hline
\end{tabular}

Furthermore, the simulation experiments showed that the output rate of the manufacturing cell depends on the number of operators working in the cell. For reasons of cost minimisation, it is common industrial practice to minimise the number of operators working in the cell. The manufacturing cell analysed consisted of five work systems, the minimum number of operators was one. The manufacturing cell operating curves shown in Figure 5 demonstrate the effect that reductions of number of operators have on the output rate. The curves in the diagram were calculated for a manufacturing cell configuration in which the work systems rather than the operators represent the bottlenecks of the cell. The separate points in the diagram show the results recorded during the simulation experiments. One can see that reducing the number of operators in the cell to one leads to a loss in the mean output rate of c. $20 \%$. Correspondingly, the mean throughput time of orders exceeds the values that are possible if enough operators are working in the cell. In comparison to configurations with more staff, using a single operator still causes a reduction of the mean output rate of around $8 \%$. Companies therefore have to reach a suitable trade-off the between the costs of production and the output that their manufacturing cells can produce. 


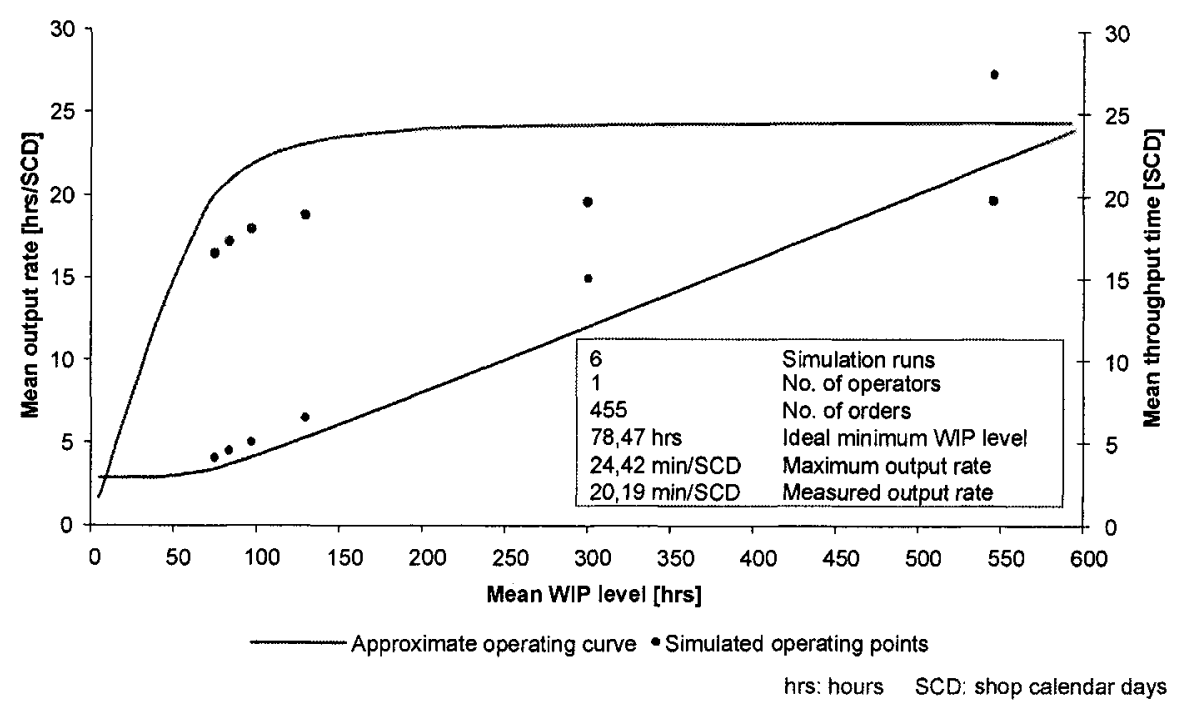

Figure 5. Impact of number of operators on logistic performance

\section{CONCLUSIONS}

The simulation experiments on a model of a manufacturing cell prove that different configurations of the interactions between human operators and work systems in manufacturing cells have different logistic properties. For some configurations, operators represent the logistic bottlenecks that determine the cycle time of the manufacturing cell and, as a consequence, its logistic performance. If it is possible to determine the operator cycle time, the theory of the logistic manufacturing operating curves serves as a modelling methodology for manufacturing cell logistics, with which the logistic adequacy of operator-work system assignments can be evaluated. The operating curves can be utilised to explain the effects of certain logistic configurations and also to predict the logistic performance of cells that are still at an implementation stage. In this way, industrial practitioners are assisted in finding those set-ups of manufacturing cells, including human operators that allow companies to achieve the logistic performance levels required. 


\section{REFERENCES}

CIEMINSKI, Gregor von; NYHUIS, Peter:

Human Aspects of the Logistics of Manufacturing Cells.

In: Human Aspects in Production Management.

Eds.: ZÜLCH, Gert; STOWASSER, Sascha; JAGDEV, Harinder S.

Aachen: Shaker Verlag, 2003, pp. 209-215.

(esim - European Series in Industrial Management, Volume 5)

GREEN, T. J.; SADOWSKI, R. P.:

A Review of Cellular Manufacturing Assumptions and Advantages and Design

Techniques.

In: Journal of Operations Management,

Amsterdam et al, 4(1984)2, 85-97.

MILTENBURG, J.:

One-piece Flow Manufacturing in U-shaped Cells: a Tutorial.

In: IIE Transactions,

London, 33(2001)4, pp. 303-321.

SCHONBERGER, R:

Building a Chain of Customers.

London: Hutchinson Business Books, 2nd ed., 1990.

SLACK, N.; CHAMBERS, L.; JOHNSTON, R.:

Operations Management.

London: FT Prentice Hall, 3rd ed., 2000.

TAKEDA, H:

Das System der Mixed Production.

Landsberg: Verlag Moderne Industrie, 1996.

WIENDAHL, H.-P.; CIEMINSKI, G. von:

Logistic Manufacturing Cell Operating Curves - Modelling the Logistic Behavior of

Cellular Manufacture.

In: Production Engineering,

Berlin, 9(2003)2, 277-284. 